\title{
cDNA and deduced protein sequence of acetylcholinesterase from the diamondback moth, Plutella xylostella (L.) (Lepidoptera: Plutellidae)
}

\author{
Xiao-yu NI, ${ }^{1}$ Takashi Tomita, ${ }^{2}$ Shinji KasaI ${ }^{2}$ and Yoshiaki Kono ${ }^{1, *}$ \\ ${ }^{1}$ Laboratory of Applied Entomology and Zoology, Institute of Agriculture and Forestry, University of Tsukuba; Tsukuba, Ibaraki \\ 305-8572, Japan \\ ${ }^{2}$ Department of Medical Entomology, National Institute of Infectious Diseases; Shinjuku-ku, Tokyo 162-8640, Japan \\ (Received 22 May 2002; Accepted 16 October 2002)
}

\begin{abstract}
The sequence of acetylcholinesterase (AChE) cDNA from the diamondback moth (DBM), Plutella xylostella (L.) was determined. A $2.3 \mathrm{~kb}$ partial cDNA sequence, containing an ORF encoding AChE precursor with 638 amino acid residues was obtained by primer walking. The deduced protein sequence showed the highest homology to AChE of the Colorado potato beetle (CPB) and the green rice leafhopper. The DBM AChE belongs to the Drosophila melanogaster Ace-orthologous insect AChE subfamily. A single AChE gene transcript $(7.6 \mathrm{~kb})$ was detected by Northern blot analysis. This is the first report of the complete coding sequence of AChE cDNA from a lepidopteran insect.
\end{abstract}

Key words: Acetylcholinesterase; cDNA; diamondback moth; insecticide resistance

\section{INTRODUCTION}

The diamondback moth (DBM), Plutella $x y$ lostella, is the most destructive pest of cruciferous crops, especially cabbage, in the temperate and tropical zones. Continuous massive control using organophosphorus insecticides (OP) from the 1980s has brought the development of serious resistance to these insecticides in DBM. In Japan, resistance to dichlovos, prothiofos, cyanofenphos and acephate has been reported based on surveys by the Japan Plant Protection Association carried out for 1980-1983. In Southeastern Asian countries, the resistance problem has become more serious because DBM goes through its life cycle more than 15 times per year in this area. Several reports on OP resistance in DBM were reported (Cheng, 1986; Miyata et al., 1986; Sun et al., 1986) in the international workshop held in Tainan, Taiwan in 1985.

As for the resistant mechanism, enhanced activities of carboxylesterase (Sun et al., 1978; Noppun et al., 1987) and glutathion S-transferase (Cheng et al., 1983) have been pointed out as degradation factors. A decrease in sensitivity of the target enzyme, acetylcholinesterase (AChE), to OP has also been proposed (Sudderuddin and Kok, 1978; Nop- pun et al., 1983).

Insensitive AChE has been shown in more than 30 insecticide resistant pest species since the first report on OP resistant strains of the two spotted spider mite (Smissaert, 1964; Voss and Matsumura, 1964). Structural analysis of the AChE gene from Drosophila melanogaster (Hall and Spierer, 1986), the mosquitoes, Anopheles stephensi (Hall and Malcom, 1991), Aedes aegyipti (Anthony et al., 1995), Culex pipiens (Malcom et al., 1998) and Culex tritaeniorhynchus (Hidoh et al., unpublished), the Colorado potato beetle, Leptinotarsa decemlineata (Zhu and Clark, 1995), the green rice leafhopper, Nephotettix cincticeps (Tomita et al., 2000), the housefly, Musca domestica (Huang et al., 1997; Kozaki et al., 2001) and the blowfly, Lucilia cuprina (Chen et al., 2001) have been reported.

Specific amino acid substitutions at several positions in AChE confer insecticide insensitivity in $D$. melanogaster (Mutero et al., 1994) and M. domestica (Huang et al., 1997; Kozaki et al., 2001, 2002). An amino acid substitution has been found in insensitive L. decemlineata AChE (Zhu et al., 1996). However, no amino acid substitution was reported in insensitive AChEs of $N$. cincticeps (Tomita et al., 2000) and C. tritaeniorhynchus (Mori et al.,

\footnotetext{
* To whom correspondence should be addressed at: E-mail: ykono@sakura.cc.tsukuba.ac.jp
} 
2001), thus genetic changes in post translational modifications are postulated. Biochemical characters of insensitive DBM AChE were reported by Tang and Zhou (1992), however, molecular mechanisms of the insensitivity are not known. In this study, we determined the cDNA sequence of $\mathrm{AChE}$ from DBM as the first step to clarify whether its insensitivity is attributed to an amino acid substitution.

\section{MATERIALS AND METHODS}

Diamondback moths. An insecticide-susceptible strain (Kyoto strain) of the DBM was used in this study. This strain was originally collected from Kyoto, Japan in May 1981 and maintained for over 18 years in the laboratory of the Institute of Agricultural Science, Takeda Chemical Industries Ltd. without exposure to insecticides. We received this strain in 1999 and have reared it continuously in our laboratory with Japanese radish (Raphanus sativus L.). The rearing conditions were $24( \pm 2)^{\circ} \mathrm{C}$, $60( \pm 2) \%$ relative humidity and 16:8 L:D photoperiod.

Reverse transcription. RNA for cDNA walking was extracted from 30 DBM pupae by the acid guanidine-phenol-chloroform method (Chomczynski and Sacchi, 1987) with ISOGEN (Nippon Gene). Poly(A) ${ }^{+}$RNA was selected by a batch treatment method with Oligotex-dT 30 Super (Takara). cDNA for conventional RT-PCR and 3'RACE was synthesized with $\mathrm{QT}^{\prime}$ primer (CCAGTGAGCAGAGTGACGAGGACTCGTGCT CAAGCTTTTTTTTTTTTTTT) and SuperScript II reverse transcriptase (Invitrogen) under temperature conditions of $37^{\circ} \mathrm{C} 5 \mathrm{~min}, 42^{\circ} \mathrm{C} 40 \mathrm{~min}, 50^{\circ} \mathrm{C}$ $5 \mathrm{~min}$ and $55^{\circ} \mathrm{C} 5 \mathrm{~min}$.

RT-PCR. Taq DNA polymerase (Takara) was used when degenerate primers were used for PCR, while Ex Taq (Takara) was otherwise used except when noted. The 3 '-end of the degenerated primers and gene specific primers (GSP) are shown on the corresponding cDNA positions in Fig. 1.

First, an internal coding cDNA (120 bp) was primarily amplified with S1i-Ace (GArATGTGGAAyGCiAAyAC, where "i" denotes deoxyinosine and the other bases follow IUB codes) and As17-Ace (CCiCCiCCrTAiAyCCA) degenerate primers under cycling conditions of $94^{\circ} \mathrm{C} 2 \mathrm{~min}$, $48^{\circ} \mathrm{C} 60 \mathrm{~s}$, and $72^{\circ} \mathrm{C} 30 \mathrm{~s}$ for 35 cycles. Second, a downstream cDNA contig (1.1 kbp) was amplified with a GSP F12 (GGAGGATTGCCTCTATTTGAAC) and a degenerated primer As4-Ace (ACnCCCATCCAyTCnCCCCA), and then seminested PCR was performed with inner GSP F14 (ACAAGCCATTAACCGAGCGAC) and As4-Ace.

5'-RACE. A partial 5'-untranslated region (5'UTR) and the N-terminal coding sequence of the cDNA was concomitantly amplified by the cRACE method (Maruyama et al., 1995) with a 5'-Full RACE Core set (Takara) following the manufacturer's protocol. The outline of the procedure follows: cDNA was synthesized from poly $(\mathrm{A})^{+} \mathrm{RNA}$ with one 5'-phosphorylated GSP R4 (CACTAGTATTGG) and AMV reverse transcriptase, then mRNA was degraded by RNase $\mathrm{H}$, and finally the single stranded DNA was ligated with T4 RNA ligase to form a concatemerized DNA. First round PCR was conducted with the circular DNA as a template, using sense F10 (TCCGTCACCATCAGGACAAG) and antisense R9 (CGGCACCCATATGTTCAAATAG) GSPs, and then a nested PCR was conducted with the F14 described above and R8 (GTTCAAATAGAGGCAATCCTCC) GSPs. The purified PCR products $(720 \mathrm{bp})$ were directly sequenced with the R8 and R5 (GAAGTACTCGTACCGCTCTTGGT) primers.

3'-RACE. The downstream region of the coding sequence of the cDNA was amplified primarily by a conventional $3^{\prime}$-RACE method and then direct sequencing was conducted with an inner GSP, but only the translation up to Thr 560 (208 bp downstream from the 5'-position of As4-Ace prmier) was obtained as a probable sequence of insect AChE. A false cDNA sequence resulted further downstream. Thus a cassette-ligation based modified RT-PCR was used for further analysis instead of conventional 3'-RACE.

Cassette-ligation based amplification of a novel downstream sequence. Twenty-five microgram of total RNA equivalent poly $(\mathrm{A})^{+}$RNA was reverse transcribed with a 3 RAP primer $\left(3^{\prime}\right.$-poly $(\mathrm{dT})_{17}$ with an anchor sequence at its $55^{\prime}$-end, Invitrogen) and SuperScript II reverse transcriptase under the same conditions as described above, and then mRNA was degraded by RNase $\mathrm{H}$. The first strand obtained was purified with a QIAquick PCR purification kit (QIAGEN). The second strand of the cDNA was synthesized with a sense GSP F23 (GGATGACAGGAGAGAGGGCACAGGA) and 
Ex Taq by one cycle of PCR cycling, and then the double strand cDNA obtained was digested with Sau3A I (Takara). The cDNA fragments were ligated to an Sau3A I cassette (Takara) with Ligation kit Ver. 2 (Takara). cDNA was amplified with a sense GSP F30 (ACCCGCTGAACATGTCTCTTCAGTACCACACCC) and C1 primer (the sequence of which is included in Sau3A I cassette, Takara), and then nested PCR with a downstream GSP F31 (CGCGCATATCATGCAGTCTTTCACGCGGTTC) and C2 (the sequence of which is also included in Sau3A I cassette, Takara) was conducted. Finally, the PCR product (400 bp) was obtained and directly sequenced.

PCR for individual-genotyping. RNA for AChE genotyping of individual moths was extracted following the manufacturer's instructions for small scale sampling with ISOGEN. cDNA was synthesized without poly(A) ${ }^{+}$RNA selection. Because of a super GC-rich portion in the bases 1949-2007 (Fig. 1), cDNA was amplified with F49 (TCGAGGTCTCCTGTACCTGTTG) and R51 (GAATGTGTCTATCTCCGTCTTC) GSPs, using Advantage GC-rich polymerase (BD Biosciences) with GC Melt according to the manufacturer's instructions. Semi-nested PCR was conducted with F50 (TATTCGCGAGCGAGTGAGAAG) and R51 GSPs, then a $2.1 \mathrm{~kb}$ sequence (bases 137-2185 of Fig. 1) was directly sequenced with inner GSPs (not shown).

DNA sequencing. Sequencing reactions were performed with purified PCR products $(0.15 \mathrm{pmol})$ and a GSP (3.2 pmol) following the instructions in the dRhodamine Terminator mix (PE Applied Biosystems, Foster, CA) and analyzed on a Genetic Analyzer 377 system (PE Applied Biosystems).

Northern blot analysis. A cDNA sequence (950 bp, bases 116-1069 in Fig. 1) was amplified by PCR with F50 and R33 (GACAACATGTGTAGACTCACG) GSPs, the purified PCR product was cloned into a plasmid TA Vector (Sambrook and Russell, 2001), and the insert was confirmed by sequencing. The purified plasmid (100 pg) was labeled by PCR with digoxigenin-11-dUTP from a Dig High Prime PCR Labeling kit (Roche) and used as a probe.

RNA was extracted from pupae with ISOGEN, and poly $(\mathrm{A})^{+}$RNA purfication was performed as described above. Poly $(\mathrm{A})^{+}$RNA equivalent to $250 \mu \mathrm{g}$ of total RNA was separated by $1 \%$ agarose gel containing formaldehyde, blotted (Koetsier et al., 1993) onto a nylon membrane (Hybond $\mathrm{N}^{+}$, Amersham) by the alkaline transfer method and fixed to a nylon membrane by baking at $120^{\circ} \mathrm{C}$ for $30 \mathrm{~min}$. Hybridization and washing conditions were according to the manufacturer's instructions (Dig High Prime DNA Labeling and Detection Starter Kit II, Roche).

The chemical luminescence signal was exposed to an X-ray film (Amersham Biosciences) for 20 min (Holtke et al., 1995).

Bioinformatic analysis of cDNA and its deduced amino acid sequences. Signal peptide was predicted by the SignalP program 2.0 (Nielsen et al., 1997, 1999, http://www.cbs.dtu.dk/services/ SignalP-2.0/). Protein sequences were aligned by the Clustal X program 1.6.6 (Thompson et al., 1994, 1998). A rooted phylogenetic tree with AChE1 of Caenorhabditis elegans (Arpagaus et al., 1994) as the outgroup was constructed by GENETYX-MAC Ver 11.0 (Software Development) based on a maximum likelihood method by the Puzzle program 4.0 (Strimmer and von Haeseler, 1996) with the following optional process: quartet sampling and an UPGMA tree (Perriére and Goudy, 1996) for parameter estimation, a JTT model (Jones et al., 1992) for the substitution process, a model of gamma distributed rates for rate heterogeneity, and 1,000 fold puzzling steps.

\section{RESULTS AND DISCUSSION}

A contiguous cDNA sequence with a total length of $2.3 \mathrm{~kb}$ containing an ORF encoding an $\mathrm{AChE}$ precursor with 638 amino acid residues was determined by primer walking, based on the mass sampling of moths from the Kyoto strain. The $5^{\prime}$ - and cassette ligation-based RT-PCR RACEs were repeated three times independently, and no gap generating segments were found in the alignment among the replicates (data not shown). Then, a shorter internal sequence of $2.1 \mathrm{~kb}$ (bases 1372185 in Fig. 1) was amplified and directly sequenced based on a single moth. A fixed cDNA sequence probably derived from a homozygote for an AChE allele was obtained from the moth and deposited in the GenBank (No. AY061975). Figure 1 shows the cDNA and deduced protein sequences of AChE. The start codon was determined by the presence of one putative stop codon (bases 10-12) 


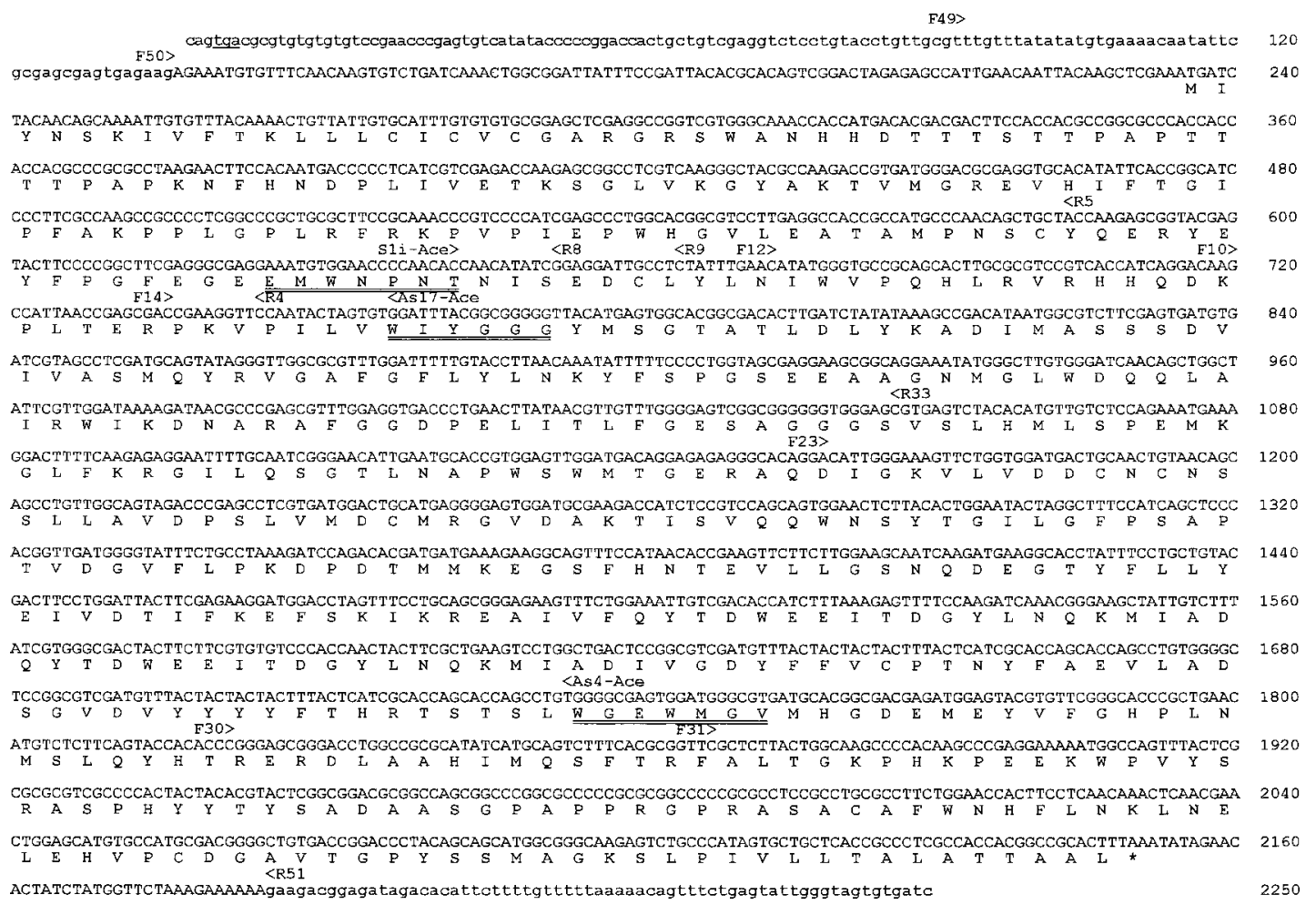

Fig. 1. The cDNA and deduced protein sequences of AChE in Plutella xylostella. The cDNA sequence from base 137-2185 was obtained from a single moth of the Kyoto strain and the other marginal sequences were obtained based on mass extraction from the same strain. Double underlines in the amino acid sequence correspond to the conserved regions from which the degenerate primers were designed. A tag beside each inequality sign indicates the corresponding primer name. Underlines in the $5^{\prime}-\mathrm{UTR}$ shows potential termination codon present in the same frame as the AChE ORF.

in the same frame of the sequence (Fig. 1).

Northern blot analysis showed a single $7.6 \mathrm{~kb}$ transcript of the DBM AChE gene (Fig. 2). The size estimated for DBM AChE mRNA is unexpectedly large, compared to $1.9 \mathrm{~kb}$ for the coding sequence. The Colorado potato beetle (CPB), L. decemlineata, also has a single large $13.1 \mathrm{~kb}$ transcript of the AChE gene (Zhu and Clark, 1995). Although the transcripts in CPB and DBM were larger than those of D. melanogaster $(4.5-4.8 \mathrm{~kb}$, Hall and Spierer, 1986), they were within the range of those found in Torpedo californica $(2.2-20 \mathrm{~kb}$, Schumacher et al., 1986). As for CPB AChE cDNA, a putative polyadenylation signal appears 731 bases downstream of the stop codon in 900 bases of the 3'-UTR from a $2.9 \mathrm{~kb}$ AChE cDNA clone, but the poly $(\mathrm{T})$ track was not observed, probably because of cleavage of the cDNA molecule in the $3^{\prime}$-UTR prior to ligation to the adaptors for vector-insertion (Zhu and Clark, 1995). Thus it is suggested that the polyadenylation signal is even much further towards the $3^{\prime}$-end and a larger $3^{\prime}$ -
UTR is involved in CPB AChE mRNA. The DBM AChE cDNA may also contain an extremely long $3^{\prime}$-UTR as suspected in the CPB AChE cDNA.

After determination of the central part of the cDNA (bases 645-1735), conventinal 3'-RACE was conducted with not less than 25 primer combinations, using oligo (dT) RT primers linked to each of five different anchor sequences. The corresponding anchor PCR primers and five different forward GSPs were analyzed under various cycling conditions. However, all cases resulted in anticlimax PCR products (i.e. AChE-like upstream and unrelated downstream sequences) or completely false positive PCR products. The most successful 3'RACE resulted in a AChE-like sequence ending at amino acid sequence number $560 \mathrm{Thr}$. Although the cause of anticlimax PCR products is not presently known, the extremely GC-rich portion of the downstream segment (bases 1949-2007) or putative long 3 '-UTR, or probably both conditions might have promoted erroneous fusions between incompletely elongated (or halting) AChE-like up- 


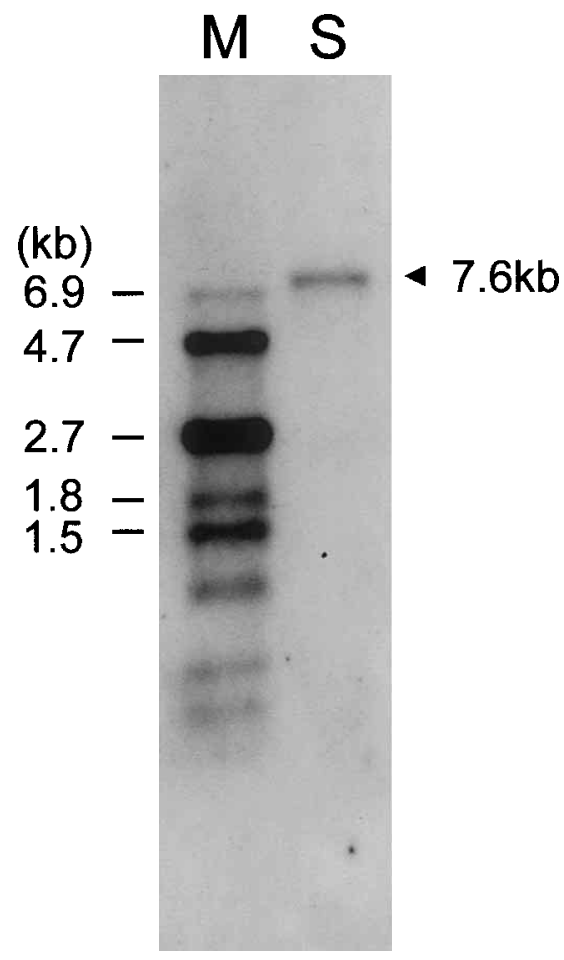

Fig. 2. Northern blot analysis of AChE mRNA from the diamondback moth, Plutella xylostella. Poly(A) ${ }^{+}$RNA equivalent to $250 \mu \mathrm{g}$ of total RNA (S) and RNA molecular weight marker (M) were separated by agarose gel electrophoresis, transferred to nylon membrane and hybridized with an AChE cDNA probe.

stream strands and unrelated downstream strands during PCR cycling.

Finally, this problem was overcome by a modified PCR based on ligation of double strand cDNA restriction fragments to their compatible cassettes. The possibility of artifacts for the novel downstream sequences, including the $\mathrm{C}$-terminal coding sequence and partial $3^{\prime}$-UTR sequence, was tested with a confirmatory semi-nested PCR using a set of forward and reverse GSPs assigned to 5' - and 3'-UTR, respectively. A shorter internal sequence of $2.1 \mathrm{~kb}$ (bases 137-2185) was amplified from a single moth and subjected to direct-sequencing. A fixed cDNA sequence probably derived from a homozygote of an AChE allele was obtained from the moth (GenBank, accession number AY061975). The resulting sequences coincided with that from the primer walking analysis described above (Fig. $1)$.

The predicted signal peptide of DBM AChE precursor (23) is similar in size to that of CPB (19, Zhu and Clark, 1995) and N. cincticeps (22, Tomita et al., 2000). The $\mathrm{C}$ terminal region of the protein sequence also contains an insect peptide equivalent to the vertebrate $\mathrm{H}$ peptide (Fig. 3). The $\mathrm{H}$ peptide has a Cys residue involved in an inter-subunit disulfide bond in the $\mathrm{N}$ proximal and a cluster of hydrophobic residues in the $\mathrm{C}$ proximal half. Hydropathy profiles for the mature protein sequence, the $3 \mathrm{D}$ and $2 \mathrm{D}$ prediction of $\mathrm{DBM}$ AChE showed the most similarity to the AChE of D. melanogaster (Harel et al., 2000) (http: //dove.embl-heidelberg.de/3D/) and the AChE of Pacific electric ray, T. californica (http://www. ensam.inra.fr/cholinesterase/Mutations/), respectively (not shown). The DBM AChE belongs to the D. melanogaster Ace-orthologous insect AChE subfamily.

The six Cys residues involved in intra subunit disulfide bonds and three residues, Ser, Glu and His involved as a catalytic triad are also conserved in the protein sequence of DBM AChE (Fig. 3). A choline binding site, Trp175, and other aromatic residues of the catalytic gorge are conserved in DBM AChE as well as in vertebrate and other insect AChEs (Fig. 3).

The similarities among amino acid sequences of DBM, $L$. decemlineata and $N$. cincticeps were compared in the alignment window from $\mathrm{Val}_{28}$ to $\mathrm{Val}_{611}$ of the DBM position numbers (Fig. 3). There are 365 identical sites in either of the three single pairs of sequences that correspond to about $60 \%$ of the precursor sequence. In these sites, positional identity between DBM and $L$. decemlineata, DBM and $N$. cincticeps were $66 \%$ and $63 \%$, respectively. A molecular phylogenetic tree including seven other complete AChEs of insects is shown in Fig. 4. The tree also apparently indicates that DBM AChE belongs to the D. melanogaster Ace-orthologous insect AChE family.

Genetic and biochemical mechanisms of insecticide-insensitive AChE have not been well understood except for several cases in which insensitive $\mathrm{AChE}$ is due to amino acid substitution mutations resulting in a structural change of the gene as reported for D. melanogaster (Mutero et al., 1994), M. domestica (Huang et al., 1997; Kozaki et al., 2001), Lucilia cuprina (Chen et al., 2001) and $L$. decemlineata (Zhu et al,. 1996). On the other hand, no specific point mutations were attributable to insensitive AChE for C. pipiens (Malcom et al., 1998) and $N$. cincticeps (Tomita et al., 2000), while 


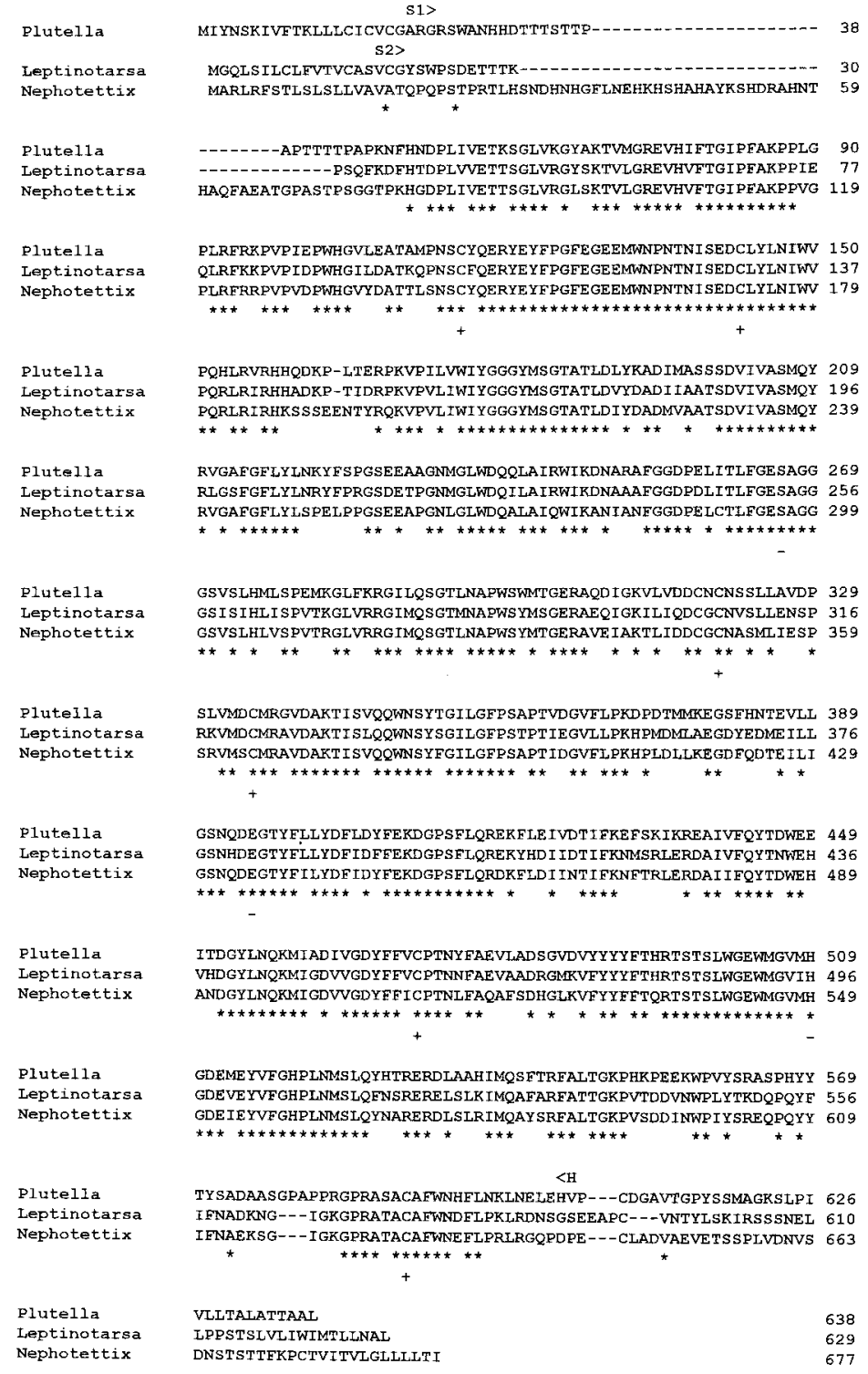

Fig. 3. Alignment of AChE precursor sequences of three insect species. Sequences from top to bottom denote the AChEs of Leptinotarsa decemlineata, Colorado potato beetele, Nephotettix cincticeps, green rice leafhopper and Plutella xylostella, diamondback moth. An inequality sign with S1 (or S2) tag indicates the predicted C-terminus of the signal peptide in $P$. xylostella (or L. decemlineata, and $N$. cincticeps). An inequality sign with $\mathrm{H}$ tag indicates the tentative $\mathrm{N}$-terminus of insect peptides equivalent to vertebrate H peptides. "Pluses" indicate the seven cysteines in intra (the former six Cys) or inter (the last one) subunit disulfide bonds. "Minuses" indicate the three residues involved in the catalytic triad. "Asterisks" indicate identical amino acid residues among the three sequences.

neither Ace-orthologous gene duplication nor the presence of Ace-paralogous second AChE gene have been exemplified to date in insect species. In C. pipiens (Malcolm et al., 1998) and C. tritaeniorhynchus (Mori et al., 2001), the genetic factor responsible for insecticide insensitivity of $\mathrm{AChE}$ is located on a chromosome other than the Ace-orthologous structural gene already identified. In such insects, whether of the point mutations are re- sponsible for the resistance in the unkown second AChE structural loccus or genetic changes are responsible for the post-translational modification remains controversial at present. This is the first report of an AChE cDNA sequence from a lepidopteran species. Whether either of the two hypothetical genetic mechanisms of insensitive $\mathrm{AChE}$ are important in DBM remains to be elucidated. Analysis of structural changes in AChE of resistant 


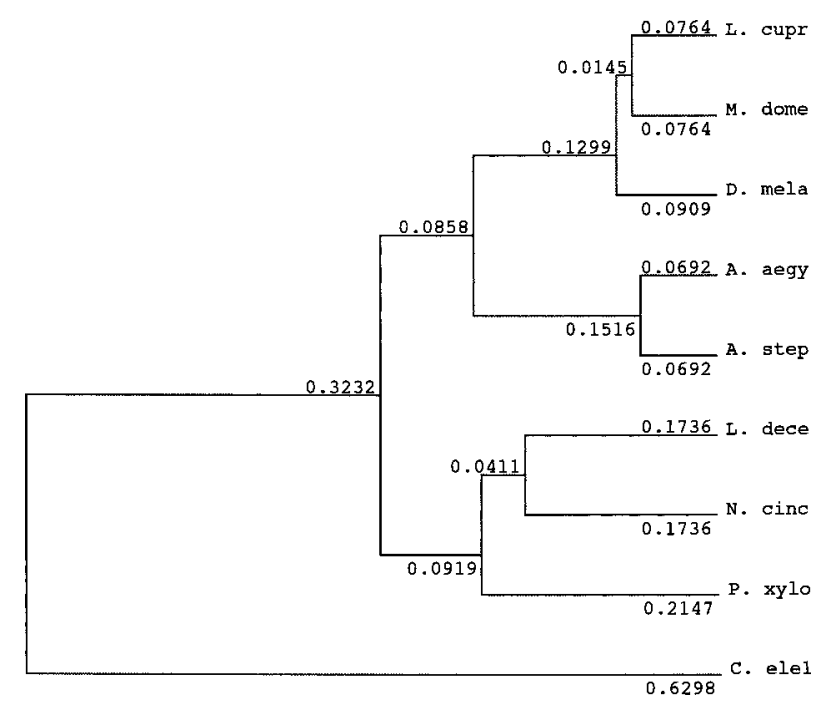

Fig. 4. Molecular phylogenetic tree of insect acetylcholinesterases. The labels C. ele1, P. xylo, N. cinc, L. dece, A. step, A. aegy, D. mela, M. dome and L. cupr denote AChE from AChE1 of Caenorhabditis elegans, Plutella xylostella, Nephotettix cincticeps (Tomita et al., 2000), Leptinotarsa decemlineata (Zhu and Clark, 1995), Anopheles stephensi (Hall and Malcom, 1991), Aedes aegypti (Anthony et al., 1995), Drosophila melanogaster (Hall and Spierer, 1986), Musca domestica (Huang et al., 1997; Kozaki et al., 2001) and Lucilla cuprina (Chen et al., 2001), respectively.

moths is in progress for this purpose.

\section{ACKNOWLEDGEMENTS}

We thank the Institute of Agricultural Science, Takeda Chemical Industries Ltd. for providing the stock culture, Dr. DeMar Taylor for his critical reading of the manuscript, and Dr. Hiroshi Honda and Dr. Yooichi Kainoh for their support and advice on maintaining the DBM strain. This work was supported in part by a Grant-in-Aid from the Ministry of Education, Science, Sports, and Culture of Japan (Nos. 11356002, 12460020 and 14206005).

\section{REFERENCES}

Anthony, N., T. Rocheleau, G. Mocelin, H-J. Lee and R. ffrench-Costant (1995) Cloning, sequencing and functional expression of an acetylcholinesterase gene from the yellow fever mosquito Aedes aegypti. FEBS Lett. 368: 461-465.

Arpagaus, N., Y. Fedon, X. Cousin, A. Chatonnet, J. B. Berge and D. Fonurnier (1994) cDNA sequence, gene structure, and in vitro expression of ace 1 , the gene encoding acetylcholinesterase of class $A$ in the nematode Caenorhabditis elegans. J. Biol. Chem. 369: 99579965.

Chen, Z-Z., R. Newcomb, E. Forbes, J. Mckenzie and P. Batterham (2001) The acetylcholinesterase gene and organophosphorus resistance in the Australian sheep blowfly, Lucilia cuprina. Insect Biochem. Mol. Biol. 31: 805-816.

Cheng, E. Y. (1986) The resistance, cross resistance and chemical control of diamondback moth. In Diamondback Moth Management: Proceeding of the First International
Workshop (N. S. Talekar and T. D. Griggs eds.). Asian Vegetable Research and Development Center, Tainan, Taiwan, pp. 329-345.

Cheng, E. Y., T. M. Chou and C. H. Kao (1983) Insecticide resistance study in Plutella xylostella (L.). IV. The activities of glutathione S-transferase in the organophorus-resistant strains. J. Agric. Res. China 32: 373-378.

Chomczynski, P. and N. Sacchi (1987) Single-step method of RNA isolation by acid guanidium thiocyanate-phenolchloroform extraction. Anal. Biochem. 62: 156-169.

Hall, L. M. C. and C. A. Malcom (1991) The acetylcholinesterase gene of Anopheles stephensi. Cell Mol. Neurobiol. 11: 131-141.

Hall, L. M. C. and P. Spierer (1986) The Ace locus of Drosophila melanogaster structural gene for acetylcholinesterase with an unusual $5^{\prime}$ leader. $E M B O \mathrm{~J} .5$ : 2949-2954.

Harel, M., G. Kryger, T. L. Rosenberry, W. D. Mallender, T. Lewis, R. J. Fletcher, J. M. Guss, I. Silman and J. L. Sussman (2000) Three-dimensional structures of Drosophila melanogaster acetylcholinesterase and of its complexes with two protein inhibitors. Protein Sci. 9: 1063-1072.

Holtke, H. J., W. Ankenbauer, K. Muhlegger, R. Rein, G. Sager, R. Seibl and T. Walter (1995) The digoxigenin (DIG) system for non radioactive labeling and detection of nucleic acids-An overview. Cell. Mol. Biol. 41: 883-905

Huang, Y., C-L. Qiao, M. S. Williamson and A. L. Devonshire (1997) Characterization of the acetylcholinesterase gene from insecticide-resistant houseflies (Musca domestica). Chin. J. Biotech. 13: 177-183 (in Chinese with English summary).

Jones, D. T., W. R. Taylor and J. M. Thornton (1992) The 
rapid generation of mutation data matrices from protein sequences. CABIOS 8: 275-282.

Koetsier, P. A., J. Schorr and W. Doerfler (1993) A rapid optimal protocol for downward alkaline Southern blotting of DNA. BioTechniques 15: 260-262.

Kozaki, T., T. Shono, T. Tomita and Y. Kono (2001) Fenitroxon insensitive acetylcholinesterase of the housefly, Musca domestica associated with point mutations. Insect Biochem. Mol. Biol. 31: 991-997.

Kozaki, T., T. Tomita, K. Taniai, M. Yamakawa and Y. Kono (2002) Expression of two acetylcholinesterase genes from organophosphate sensitive- and insensitive-houseflies, Musca domestica L. (Diptera: Muscidae), using a baculovirus insect cell system. Appl. Entomol. Zool. 37: 213-218

Malcolm, C. A., D. Bourguet, A. Ascolillo, S. J. Rooker, C. F. Garvey, L. M. Hall, N. Pasteur and M. Raymond (1998) A sex linked Ace gene, not linked to insensitive acetylcholinesterase mediated insecticide resistance in Culex pipiens. Insect Mol. Biol. 7: 107-120.

Maruyama, I. N., T. L. Rakow and H. I. Maruyama (1995) cRACE: a simple method for identification of the $5^{\prime}$ end of mRNAs. Nucleic Acids Res. 23: 3796-3797.

Miyata, T., T. Saito and V. Noppun (1986) Insecticide resistance in diamondback moth. In Diamondback Moth Management: Proceeding of the First International Workshop (N. S. Talekar and T. D. Griggs eds). Asian Vegetable Research and Development Center, Tainan, Taiwan, pp. 347-357.

Mori, A., T. Tomita, O. Hidoh, Y. Kono and D. W. Severson (2001) Comparative linkage map development and identification of an autosomal locus for insensitive acetylcholinesterase-mediated insecticide resistance in Culex tritaeniorhynchus. Insect Mol. Biol. 10: 197-203.

Mutero, A., M. Pralavorio, J-M. Bride and D. Fournier (1994) Resistance-associated point mutations in insecticideinsensitive acetylcholinestarese. Proc. Natl. Acad. Sci. USA 91: 5922-5926.

Nielson, H., S. Brunak and G. Heijne (1999) Machine learning approaches to the predication of signal pestides and other protein sorting signals. Protein Engineering 12: 3-9.

Nielson, H., Y. Engelbrecht, S. Brunak and G. Heijne (1997) Identification of prokaryotic and eukaryotic signal peptides and prediction of their cleavage sites. Protein Engineering 10: 1-6.

Noppun, V., T. Miyata and T. Saito (1983) Susceptibility of four strains of the diamondback moth, Plutella xylostella (L.) against insecticide. J. Pestic. Sci. 8: 595-599.

Noppun, V., T. Miyata and T. Saito (1987) Insensitivity of acetylcholinesterase in phenothoate resistant diamondback moth, Plutella xylostella (L.) (Lepidoptera: Yponomeutidae). Appl. Entomol. Zool. 22: 116-118.

Perriére G. and M. Goudy (1996) WWW-Query: An on-line retrieval system for biological sequence banks. Biochimie 78: 364-369.

Sambrook, J. and D. Russell (eds.) (2001) Molecular
Cloning: A Laboratory Manual. 3rd ed. Cold Spring Harbor Laboratory, New York. pp. 8.35-8.36.

Schumacher, M., S. Camp, Y. Maulet, M. Newton, K. MacPhee-Quigley, S. S. Taylor, T. Friedmann and P. Taylor (1986) Primary structure of Torpedo californica acetylcholinesterase deduced from its cDNA sequence. Nature 319: 407-409.

Smissaert, H. R. (1964) Cholinesterase inhibition in spider mites susceptible and resistant to organosphosphate. Science 143: 129-131.

Strimmer, K. and A. von Haeseler (1996) Quartet puzzling: a quartet maximum likelihood method for reconstructing tree topologies. Mol. Biol. Evol. 13: 964-969.

Sudderuddin, K. I. and P. F. Kok (1978) Insecticide resistance in Plutella xylostella collected from the Cameron highlands of Malaysia. FAO Plant Prot. Bull. 26: 53-57.

Sun, C. N., H. Chui and H. T. Feng (1978) Diamondback moth resistance to diazion and methomyl in Taiwan. $J$. Econ. Entomol. 71: 551-554.

Sun, C. N., T. K. Wu, J. S. Chen and W. T. Lee (1986) Insecticide resistance in diamondback moth. In Diamondback Moth Management: Proceeding of the First International Workshop (N. S. Talekar and T. D. Griggs eds.). Asian Vegetable Research and Development Center, Tainan, Taiwan, pp. 359-371.

Tang, Z-H. and C-L. Zhou (1992) Acetylcholinesterase sensitivity in resistant Plutella xylostella (L.). Acta Entomol. Sinica 35: 385-392 (in Chinese with English summary).

Thompson, J. D., T. J. Gibson, F. Plewniak, F. Jeanmougin and D. G. Higgins (1998) The CLUSTAL_X windows interface: flexible strategies for multiple sequence alignment aided by quality analysis tools. Nucleic Acids Res. 25: 4876-4882.

Thompson, J. D., D. G. Higgins and T. J. Gibson (1994) CLUSTAL W: improving the sensitivity of progressive multiple sequence alignment through sequence weighting, positions-specific gap penalties and weight matrix choice. Nucleic Acids Res. 22: 4673-4680.

Tomita, T., O. Hidoh and Y. Kono (2000) Absence of protein polymorphism attributable to insecticide-insensitivity of acetylchoinesterasse in the green rice leafhopper, Nephotettix cincticeps. Insect Biochem. Mol. Biol. 30: 325-333.

Voss, G. and F. Matsumura (1964) Resistance to organophosphorus compounds in the two-spotted spider mite: Two different mechanisms of resistance. Nature 202: 319-320.

Zhu, K-Y. and J. M. Clark (1995) Cloning and sequencing of a cDNA encoding acetylcholinesterase in Colorado potato beetle, Leptinotarsa decemlineata (Say). Insect Biochem. Mol. Biol. 25: 1129-1138.

Zhu, K-Y., S-H. Lee and J. M. Clark (1996) A point mutation of acetylcholinesterase associated with azinphosmethyl resistance and reduced fitness in Colorado potato beetle. Pest Biochem. Physiol. 55: 100-108. 